\title{
Assessing Laser Cleaning of a Limestone Monument by Fiber Optics Reflectance Spectroscopy (FORS) and Visible and Near-Infrared (VNIR) Hyperspectral Imaging (HSI)
}

\author{
Costanza Cucci ${ }^{1}$ (D), Olga De Pascale ${ }^{2}$ and Giorgio S. Senesi ${ }^{2, *}$ (i) \\ 1 Institute of Applied Physics “N. Carrara”-(IFAC-CNR), 50019 Sesto Fiorentino, Italy; c.cucci@ifac.cnr.it \\ 2 Istituto per la Scienza e Tecnologia dei Plasmi (ISTP-CNR)-Sede di Bari, 70126 Bari, Italy; \\ olga.depascale@istp.cnr.it \\ * Correspondence: giorgio.senesi@cnr.it; Tel.: +39-0805929505
}

Received: 29 September 2020; Accepted: 23 November 2020; Published: 25 November 2020

\begin{abstract}
Fiber optics reflectance spectroscopy (FORS) and visible and near-infrared (VNIR) hyperspectral imaging (HSI) were applied to assess and control the laser cleaning process of a deeply darkened limestone surface collected from the historic entrance gate of Castello Svevo, Bari, Italy. Both techniques enabled us to verify the different degree of removal of a thick deposit of black crust from the surface of the walls. Results obtained were in good agreement with those of previous studies of the elemental composition achieved by application of laser-induced breakdown spectroscopy (LIBS). Coupling FORS and VNIR-HSI provided important information on the optimal conditions to evaluate the conservation status and determine the more appropriate level of cleaning restoration, thus avoiding over- and/or under-cleaning. Imaging spectroscopy was used to obtain maps of areas featuring the same or different spectral characteristics, so to achieve a sufficient removal of unwanted layers, without modifying the surface underneath, and to increase the efficiency of traditional cleaning techniques. The performance of the combined non-invasive approach used in this work shows promise for further applications to other types of rocks and highlights the potential for in situ assessment of the laser cleaning process based on reflectance spectroscopy.
\end{abstract}

Keywords: limestone monuments; laser cleaning; fiber optics reflectance spectroscopy; visible and near-infrared hyperspectral imaging

\section{Introduction}

In the past, limestones were one of the most widely used building materials for many monuments in the city of Bari and the Apulia region, Italy [1]. Limestone monuments often consist of overlapping rock layers that can be variously deteriorated, with formation of black crusts, solid concretions and corrosion layers induced by exposure to both weathering, which leads to their natural aging, and atmospheric pollution, which causes their degradation by dry and wet depositions [2,3]. These monuments thus require extensive and expensive and frequent cleaning works [3-6]. In particular, the evaluation of stratigraphy before and after the removal of deteriorated layers is relevant for performing any cleaning treatment [7]. A critical aspect to achieve a successful cleaning of altered surfaces is to determine at which surface depth the thermal, mechanical or chemical process used to remove undesired layers must be interrupted without damaging the so-called "age patina" that defines the chromatic changes of the surface caused by the interactions of the stone with the external environment, and should be preserved as it testifies the historic value of the building [8]. Different criteria-aesthetical, historical 
and technical-are adopted in the decision-making process of cleaning historical facades, but the debate on what has to be cleaned and what preserved is still far from being solved [8].

Laser ablation is a very efficient tool that is able to progressively remove layers of few microns from a stone surface, and it provides many advantages with respect to mechanical and chemical methods in terms of graduality, self-termination, selectivity, environmental impact and capability of safeguarding the "age patina" [7-16]. The evaluation of laser cleaning of cultural artifacts has been often performed by laser-induced breakdown spectroscopy (LIBS) and laser-induced fluorescence spectroscopy (LIFS) [17-19]. These methods, however, are micro destructive and not sensitive to transparent contaminants [20], and they may have some limitations for in-process and real-time monitoring. Thus, non-invasive techniques based on portable devices, such as reflectance spectroscopy in the visible (Vis), near-infrared (NIR) and short-wave infrared (SWIR) spectral ranges, are ideal candidates to assess and control the progressive ablation effects occurring during cleaning treatments of historical buildings. As extensively reported in the literature, the Vis-NIR-SWIR reflectance spectrum allows us to identify a wide class of surface constituents, whereas the Vis reflectance spectrum can be used also for the colorimetric characterization of chromatic changes possibly occurring during degradation processes.

Nowadays, fiber optics reflectance spectroscopy (FORS) implemented with portable instrumentation has become a well-established spot analytical technique for the in situ preliminary diagnostics on a variety of artworks surfaces [21-24]. Furthermore, in the last decade, hyperspectral imaging (HSI), i.e., the imaging version of reflectance spectroscopy, has emerged as a powerful tool for non-invasive diagnostics of extended polychrome surfaces in different types of cultural heritage assets [25-29]. In the Cultural Heritage sector, a well-acknowledged additional advantage of HSI over spot reflectance analysis is the enormous potentialities of multivariate analysis and statistical methods for data-processing, which can provide 2D maps and elaborated images of distributions of materials over a given surface, highlighting anomalies and non-homogeneities [27,30]. Furthermore, the HSI imaging spectrometry can achieve spatial resolutions of a centimeter or less, whereas the availability of SWIR wavelengths is crucial for mineralogical analyses, as unique overtones and combination tones of vibrations within mineral structures occur in this region (see [31] and reference there in). Despite such promising features, so far, two studies employed multi-spectral imaging techniques to assess laser cleaning treatment for removing inorganic encrustations from marble objects and fine-grained granite [32,33], whereas they have never been applied to the study of limestone weathered rocks. The documented and longtime applications of reflectance spectrometry in both fields of remote-sensing and conservation science strongly support the appropriateness of using FORS and HSI in support of laser cleaning operations on lithotypes of historic and artistic interest.

The present study was framed in a wider conservation project carried out on the Castello Svevo, Bari, Italy, aiming at exploring innovative processes and products in the large-scale restoration sector through specific research activities. The specific aim of this study was to test an innovative approach based on Vis-NIR-SWIR reflectance spectrometry implemented as FORS and HSI techniques associated with two multivariate algorithms, i.e., spectral angle mapper (SAM) and principal component analysis (PCA), for assessing and controlling the laser cleaning process and mapping layer surfaces of a deeply altered limestone fragment collected from this historical building.

\section{Materials and Methods}

\subsection{Sample}

The sample was collected from a selected block of the limestone masonry of Castello Svevo, Bari, Italy (Figure 1), which is a historic multilayered monument originally built by Roger the Norman in 1131, on the remains of a Byzantine structure. The main limestone unit used to build the castle was the "Calcare di Bari" unit, i.e., the lower and middle part of the succession outcropping in the Northwestern Murgian area, which is referred to the Valanginian-Lower Turonian age [1]. This unit 
features an irregular sequence of limestone, dolomitic limestone and dolomite that originated in a depositional environment of the inner platform zone of which micrite and sparite were the most used litho-facies in buildings and monuments in the area. The "Calcare di Bari" is chemically composed of an acid-soluble portion represented by $\mathrm{CaCO}_{3}, \mathrm{MgCO}_{3}$ and small amounts of other oxides, and an acid insoluble portion [1].
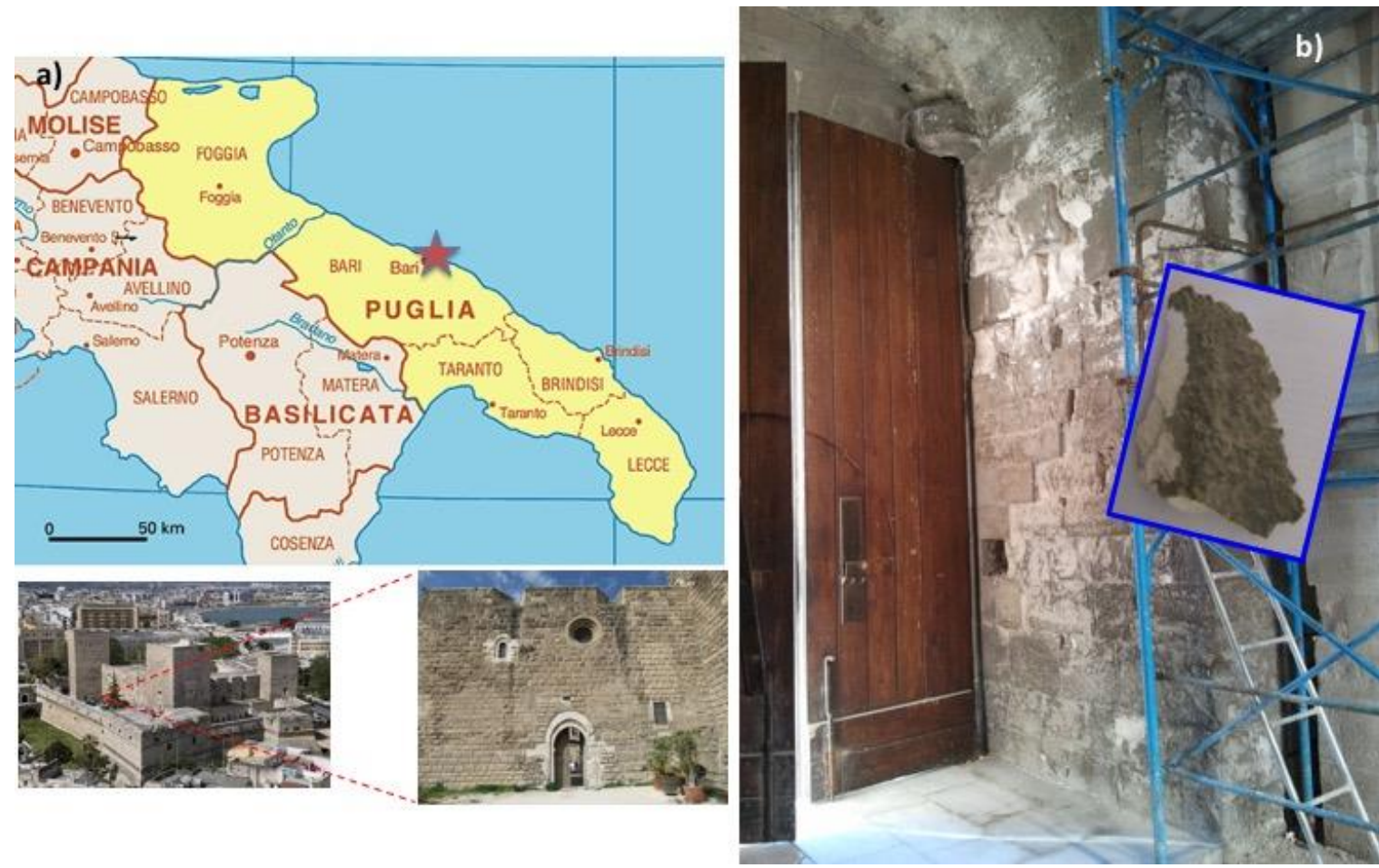

Figure 1. Map of south Italy indicating the city of Bari (red star), where the limestone masonry of Castello Svevo is located (a) and the internal castle wall from where the fragment studied (blue inset) was collected (b).

The sample used in this work has been classified as a dedolomitizated limestone in which the texture of the original rock appeared canceled by a dedolomitization process during which pseudomorfic microcrystalline calcite replaced by recrystallization the typical lozenge form of dolomite crystals [34]. Furthermore, the sample showed the presence of surface alteration with a layer of black crust consisting of a fine and opaque particulate component combined with quartz silt and bound by cryptocrystalline gypsum mixed with calcite [34].

\subsection{Laser Cleaning Procedure}

The cleaning process, which aimed to restore the original color and aspect of the bedrock and preserve the "age patina", was performed by a portable pulsed Nd:YAG Q-switched laser (mod. Thunder Art, Quanta System, Samarate-Varese, Italy), at a pulse width of $8 \mathrm{ns,} \mathrm{and} \mathrm{a} \mathrm{repetition}$ rate of $20 \mathrm{~Hz}$, equipped with a multi-articulated arm with seven folding mirrors that enabled the laser beam to travel into an aluminum tube. The laser pulse energy used was settled at $800 \mathrm{~mJ}$ for the $1064 \mathrm{~nm}$ wavelength and $400 \mathrm{~mJ}$ for the $532 \mathrm{~nm}$ wavelength with 300 pulses/min. Laser fluence (F) values were $4 \mathrm{~J} / \mathrm{cm}^{2}$ at $1064 \mathrm{~nm}$ and $6 \mathrm{~J} / \mathrm{cm}^{2}$ at $532 \mathrm{~nm}$.

Due to the presence of different types of limestone quoins with different compactness and porosity, two different laser treatments were performed to verify the level of cleaning achieved: the first one using the $1064 \mathrm{~nm}$ wavelength (treatment a), and the second one by applying two consecutive wavelengths, $1064 \mathrm{~nm}$ and then $532 \mathrm{~nm}$ (treatment b). After the removal of black crust by the $1064 \mathrm{~nm}$ treatment (treatment a), a yellowish/brownish surface was obtained, whose chromatic appearance was slightly 
different from the whitish unaltered bulk stone of the side section of the fragment, whereas the two consecutive wavelength treatments (treatment b) provided a whiter surface, which was apparently similar to the bulk stone.

\subsection{Vis-NIR-SWIR FORS and HSI Analyses}

The FORS analysis was performed by using two spectro-analyzers (MCS601 UV-NIR and MCS611 NIR 2.2 WR models, ZEISS International, Oberkochen, Germany) mounted in the same compact chassis, which also included a voltage-stabilized tungsten-halogen lamp (20W, Model CLH600). The Vis module covered the 350-900 nm range with an acquisition step of $0.8 \mathrm{~nm} / \mathrm{pixel}$ and a resolution of approximately $2 \mathrm{~nm}$, whereas the SWIR module operated in the 900-2200 nm range, with a $6 \mathrm{~nm} / \mathrm{pixel}$ acquisition step and a resolution of approximately $15 \mathrm{~nm}$. Thus, a high-resolution spectrum in the 350-2200 nm range was acquired on each spot. An optical fiber bundle, which was connected to an $8^{\circ} / 8^{\circ}$ probe-head for reflectance measurements, was used to illuminate the target and collect the reflected radiation (Figure 2a). The probe-head was used in the contact mode, following an established repositioning procedure. Spectral calibration was performed before each measurement session, using a certified white reference Spectralon ${ }^{\circledR}$ 99\% diffuse reflectance target.
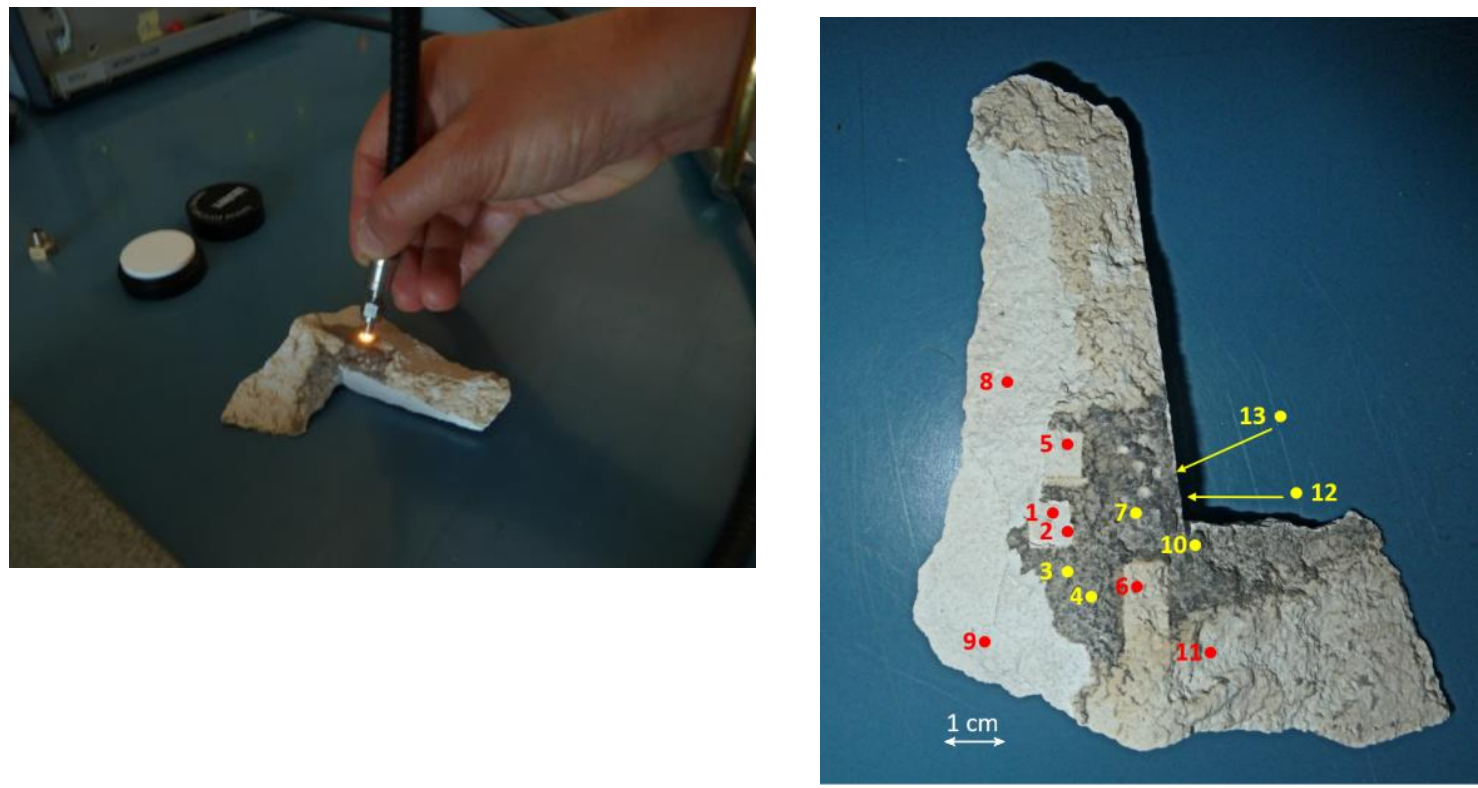

(a)

(b)

Figure 2. The optical fiber bundle illuminating the target and collecting the reflected radiation with an $8^{\circ} / 8^{\circ}$ probe-head (a). The 13 spot areas where FORS measurements were performed, treatments a and $\mathrm{b}$ (red spots) and non-cleaned zones (yellow spots) (b).

The FORS measurements were performed on a set of 13 spot areas, which were selected throughout the fragment to include zones cleaned with treatments $a$ and $b$ and non-cleaned zones (Figure 2b). The investigated spots were almost circle-shaped, with a diameter of $2 \mathrm{~mm}$.

The HSI measurements were performed by a high-performance HSI imager scanner (custom version assembled at the Istituto di Fisica Applicata Nello Carrara - CNR, Florence, Italy), and a non-commercial prototype designed to operate over the extended 400-1700 nm range, and featuring a high spatial sampling rate (about 11 points $/ \mathrm{mm}$ ), and a high spectral resolution, i.e., about $2.5 \mathrm{~nm}$ in the 400-900 range and about $8 \mathrm{~nm}$ in the $900-1700 \mathrm{~nm}$ range [35]. The HSI scanner consisted in a push-broom modular system that included two interchangeable electro-optical heads. The Vis-NIR module used a prism-grating-prism (PGP) line-spectrograph (SPECIM mod. ImSpector ${ }^{\circledR}$ V10E) connected with a high-sensitivity Si charge-coupled device (CCD) (ORCA-ER Hamamatsu), whereas the SWIR 
module used a spectrograph (SPECIM mod. ImSpector ${ }^{\circledR}$ N17E V17E) combined with a InGaAs camera (Xenics ${ }^{\circledR}$ mod. Xeva 1.7-640) designed for professional applications in the NIR/SWIR range. A telecentric objective was used to minimize geometric distortions when non-planar surfaces were imaged. The illumination module consisted of a $3200 \mathrm{~K} 150$-Watt QTH-lamp connected to two fiber-optics. The optical scan-head and the illumination module were fixed together and mounted on a mechanical scanner, allowing two high-precision movements along the orthogonal axis, on a vertical plane, in front of the target surface. Scanning was performed with a sequence of adjacent vertical scans of about $6.45 \mathrm{~cm}$ in width, slightly overlapped at the edges, and at constant scan speed of $1.5 \mathrm{~mm} / \mathrm{s}$, with the Vis-NIR head and $0.8 \mathrm{~mm} / \mathrm{sec}$ with the SWIR head. The overall spatial sampling was about 11 points/mm in the Vis-NIR and 9.2 points/mm in the SWIR, which provided highly spatially resolved spectral images. The scanner acquired 750 spectral images in the $400-1700 \mathrm{~nm}$ range. The acquired dataset, whose size was of order of one Gigabyte, is called "data cube" or "image cube", due to its inherent three-dimensionality, where each datum is univocally identified by two spatial coordinates ( $x$ and $y$ ), which locate the pixel within the imaged area, and a third spectral coordinate $(\lambda)$, which refers to the intensity of the radiation reflected at a given wavelength. The image cube can be considered either as a collection of images (an image for each band) or as a collection of reflectance spectra (a spectrum for each pixel).

The main drawback of the HSI IFAC CNR scanner is its scarce portability, which makes it a device suitable for laboratory but not field applications. However, portable compact HSI cameras have been recently commercialized, which opened novel applicative perspectives in outdoors environment. Thus, in the perspective of testing the applicability of HSI to laser ablation control in the field, the HSI data acquired in the 400-900 $\mathrm{nm}$ and 900-1700 nm ranges were separately analyzed and compared to achieve the informative contents of both Vis-NIR and SWIR spectral ranges.

\subsection{Data Treatment with PCA and SAM}

The ENVI ${ }^{\circledR}$ Software (v.5.01, L3Harris Geospatial ${ }^{\mathrm{TM}}$, Melbourne, FL, USA) was used to process experimental HSI data cubes by applying two multivariate algorithms, i.e., PCA [36] and SAM [37,38]. PCA is a well-established method used for data compression, to reduce the dimensionality of the original dataset, and consists in a linear transformation able to reorganize the original image-cube into a new set of elaborated images with reduced dimensionality. By this method, the original dataset comprising hundreds of spectral bands is scaled down to a few (typically up to 10) principal component (PC) images that represent uncorrelated linear combinations of input bands [36].

Differently, the SAM algorithm is commonly used to classify spectral data based on their similarity with a given reference spectrum, named "endmember". This algorithm classifies the pixels on the basis of their spectral similarity by calculating the "spectral angle" between the two spectra, which are treated as vectors in a space with dimensionality equal to the number of bands. The method is insensitive to spectral intensity; thus, it is suitable to treat spectral data acquired in the field, especially in cases of non-ideal illumination conditions that may cause uncontrolled variations in reflectance intensities. These methods were expected to enable the classification and mapping of the limestone fragment according to spectral similarities and provide elaborated images of investigated areas by highlighting features that cannot be detected by visual inspection.

\section{Results and Discussion}

A preliminary visual inspection of the fragment showed that laser pulses of few ns at $1064 \mathrm{~nm}$ produced a partial removal of the black crust surface likely due to the rapid temperature increase, which resulted in a yellowish/brownish color of the stone surface. Further irradiation of the previously cleaned areas with the second harmonic $(532 \mathrm{~nm})$ seemed to completely remove the black crust and retrieve the original color of the bulk stone, which was visible in the side section of the fragment.

The primary aim of the spectroscopic analysis was to identify the areas cleaned by laser and possible spectral markers useful to assess the degree of cleaning level. The FORS data acquired 
on the selected areas were then comparatively analyzed by Vis-NIR-HSI, so to provide a better characterization of the fragment and map the degree of cleaning of the selected areas.

\subsection{Vis-NIR-FORS}

The spectra acquired by FORS in the 350-2200 nm range were analyzed preliminarily, to investigate the compositional features of the differently treated surfaces and identify their diagnostic spectral markers. By this procedure, the 13 FORS spectra could be classified into four main groups featuring a similar spectral behavior. Representative spectra of each group are shown in Figure 3 and discussed below.

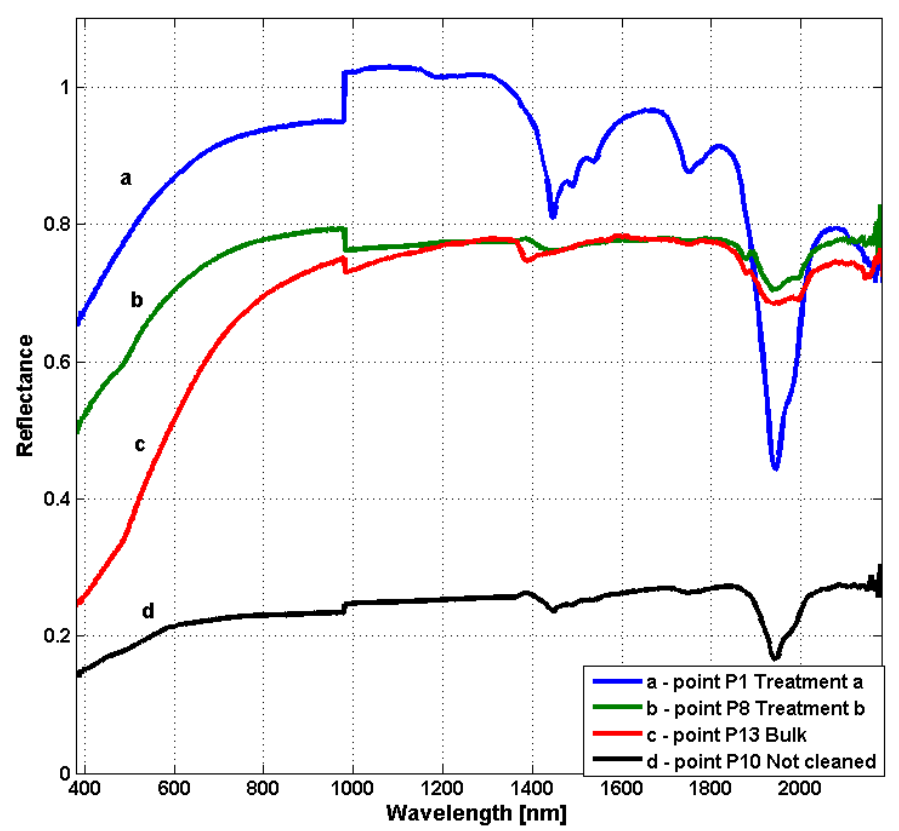

(a)

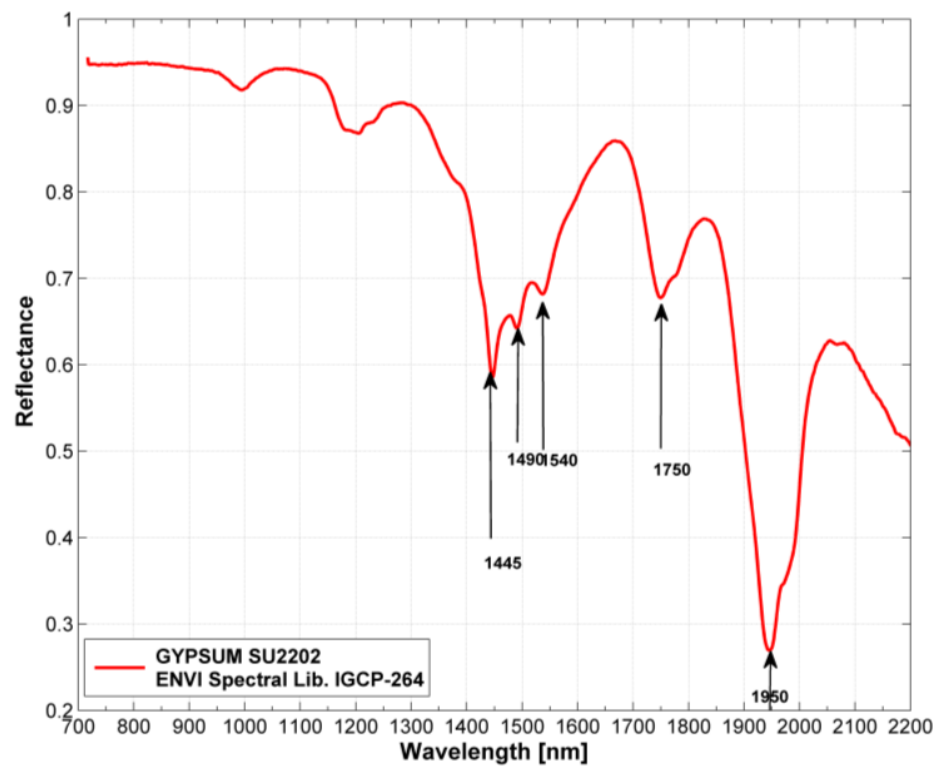

(b)

Figure 3. The four types of Vis-NIR reflectance spectra acquired by FORS (a), and a reference reflectance spectrum of gypsum (GYPSUM_SU2202 from ENVI Spectral Library IGCP-264 Project CSES Beckman) (b). 
The FORS spectra of type a (Figure 3a) were all acquired on the areas laser-cleaned with the wavelength of $1064 \mathrm{~nm}$ (spots P1, P5, P6 and P11 in Figure 2b) and were all similar. These spectra featured the typical pattern of gypsum (calcium sulfate dihydrate, $\mathrm{CaSO}_{4} \cdot 2 \mathrm{H}_{2} \mathrm{O}$ ) (Figure $3 \mathrm{~b}$ ), which consisted of (a) a triplet of three absorption bands centered at 1445, 1480, and $1535 \mathrm{~nm}$ attributed to the first overtone of the $\mathrm{O}-\mathrm{H}$ stretching of the structured water; and (b) the two combination bands at 1750 and $1990 \mathrm{~nm}$ [39]. With gypsum being a typical alteration product of limestone, the presence of its signals indicated that, although the black crust visually disappeared, the weathered layer was not removed completely.

The spectra of type $b$ (Figure 3a) corresponded to areas cleaned using the two-wavelengths treatment (spots P2, P8 and P9 in Figure 2b). In these spectra, the gypsum signals were reduced strongly, or absent, which indicated the effectiveness of the cleaning treatment in removing the weathered surface down to the unaltered fresh stone (bulk) inner layers. This result was confirmed by the similarity of these spectra to those of type $\mathrm{c}$ which were acquired on two points on the bulk stone that were not affected by weathering (spots P12 and P13 in Figure 2b). The spectra of type d were acquired on untreated weathered areas (spots P3, P4, P7 and P10 in Figure 2b). Due to the high absorbance of the black crust, these spectra featured an overall low reflectance intensity, although gypsum bands were still detectable at a much lower intensity, as expected.

Although less evident, different spectral features between the four groups were also observable in the Vis regions, according to the different color appearing on the corresponding areas of the surface. In particular, the reflectance spectra of surfaces subjected to laser cleaning at both wavelengths (Figure 3a, type b) and those of the bulk stone surfaces (Figure 3a, type c) featured a slight absorption signal at $490 \mathrm{~nm}$, likely due to the presence of iron-oxides-based pigments, which confirmed that this type of cleaning was likely able to remove weathered layers, down to the original stone surface.

\subsection{Vis-NIR-HSI}

The results of the FORS analysis, which showed that different spectral features could be associated to differently treated areas, encouraged the use of HSI to map the distinct zones of the fragment. Figure $4 \mathrm{a}$ indicates the three points corresponding to different treated areas of the limestone fragment which were used to extract the reflectance spectra from the Vis cube-image (Figure $4 \mathrm{~b}$ ) and the NIR cube-image (Figure 4c). As the HSI spectra were qualitatively comparable with those measured by FORS, HSI was tested to extract the same compositional information with the additional advantage of the imaging approach that relates each reflectance spectrum to its position in the image, thus allowing the use of multivariate and statistical methods. The PCA treatment applied to HSI data yielded a set of grayscale images (PC images) that could be used to visually distinguish areas with different spectral features. Both Vis and NIR HSI-data cubes were processed separately by PCA, which enabled to extract new false color maps that allowed us to visualize the different materials distributions and their abundances on the surface, so providing an immediate view of the differently cleaned areas that were not easily detectable by the naked eye.

As a first step, PCA was applied to the Vis data in the 420-885 nm range. The first three PC images, which accounted for $99.8 \%$ of the cumulative variance, were combined in the three-chromatic red-green-blue (RGB) channels, so yielding a false-color image that highlighted the differently treated areas of the fragment. Specifically, the graph of the first three PC loadings (Figure 5) illustrates the spectral weight of each image, i.e., how each wavelength contributed to each PC. Overall, PC1 had a similar contribution from each wavelength, whereas PC2 accounted for the spectral changes in the 750-880 nm range, and PC3 depended markedly on the 400-600 nm range and, to a lesser extent, on the $600-800 \mathrm{~nm}$ range. Thus, the false-color image obtained by assigning PC1 to B, PC2 to R and PC3 the G channels clearly mapped the differently cleaned areas (Figure 6a). The cyan color (Green + Blue, influenced by PC1 and PC3) corresponded to the zones laser cleaned with a single wavelength $(1064 \mathrm{~nm})$, which resulted essentially in removing the black crust, so causing a strong change of color (from dark to white-yellow) of the surface, but did not affect the inner layer. Differently, 
the purple areas (Red + Blue) represented zones cleaned more in-depth, using the two wavelengths (1064 and $532 \mathrm{~nm}$ ), which affected the reflectance features also in the NIR region. The comparison with the visual image in Figure 4a showed that the map highlighted the shapes and sharp contours of the test-cleaning areas, thus providing a tool to promptly visualize the extent, homogeneity and type of the treatment, so enabling the discrimination of details (e.g., residual non totally cleaned zones) that were not detectable at the naked eye.

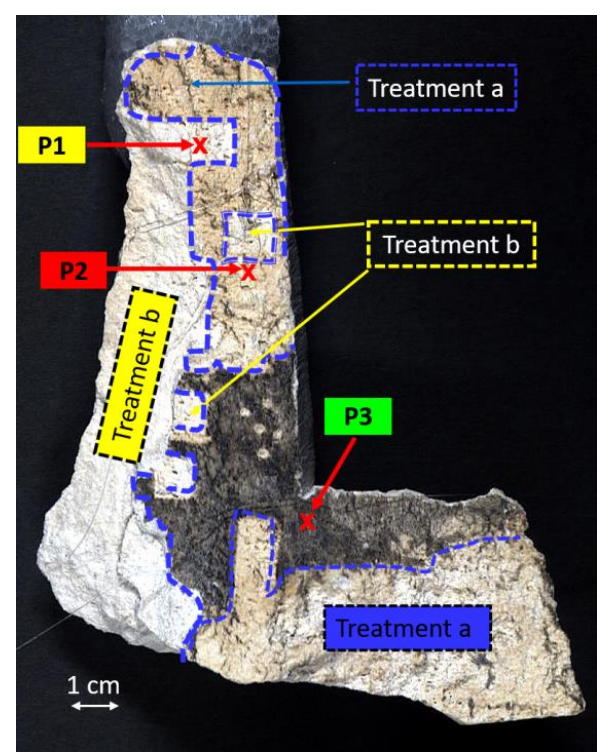

(a)

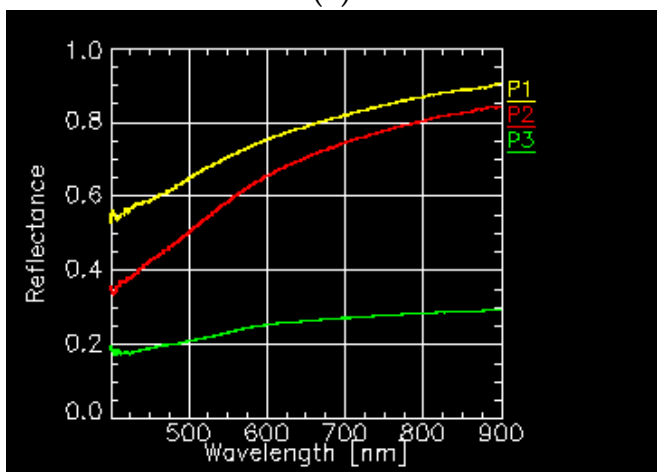

(b)

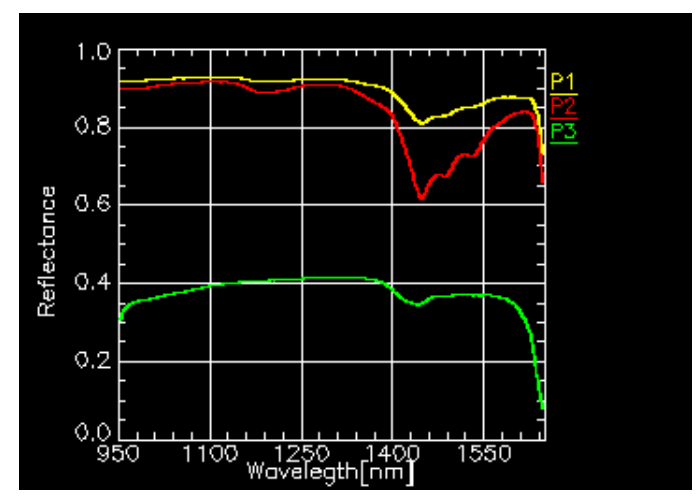

(c)

Figure 4. The RGB image reconstructed from HSI data showing the three points of the limestone fragment used to extract the HSI reflectance spectra (a), the reflectance spectra extracted from the Vis cube image (b) and the NIR cube image (c). 


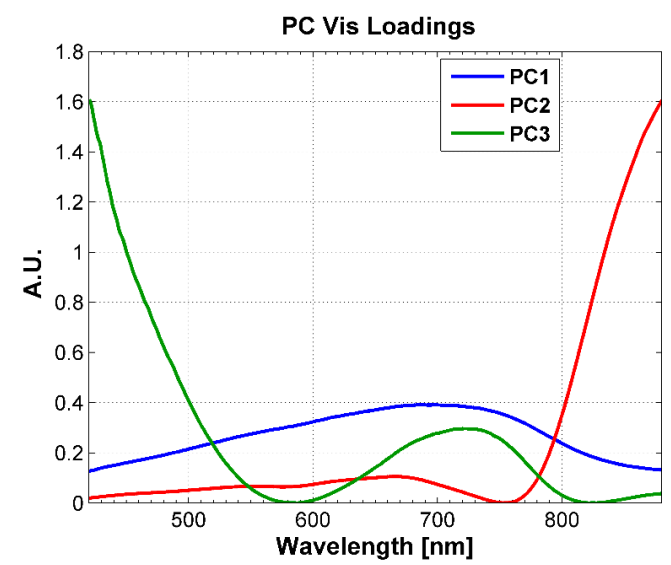

(a)

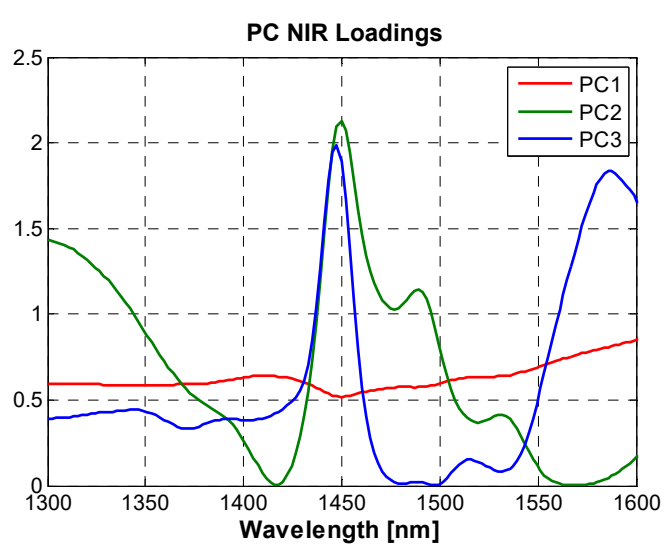

(b)

Figure 5. Loading plots of PC1, PC2 and PC3 images calculated in the Vis range (420-880 nm) (a) and NIR range (1300-1615 $\mathrm{nm})(\mathbf{b})$.

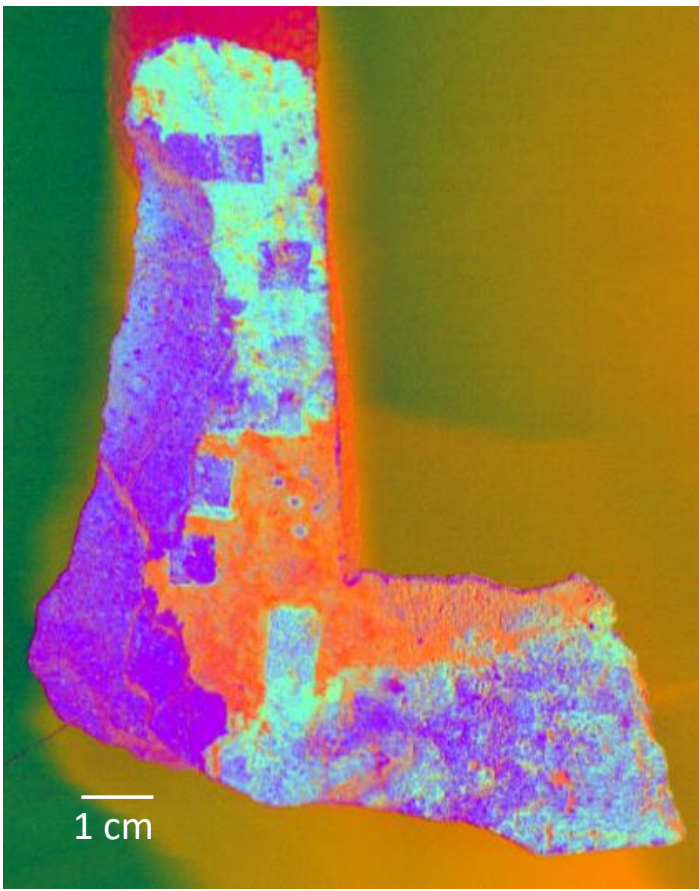

(a)

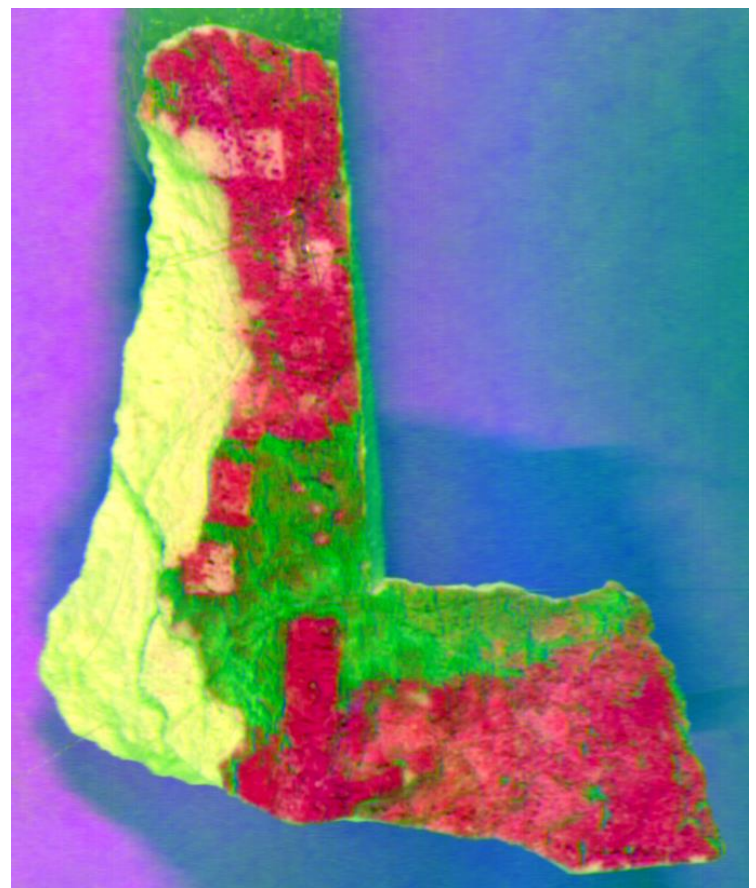

(b)

Figure 6. False color RGB maps in the Vis spectral range $(420-885 \mathrm{~nm})(\mathbf{a})$ and in the NIR spectral range $(1300-1615 \mathrm{~nm})(\mathbf{b})$.

In order to visualize the effectiveness of the treatments, the efficacy in removing gypsum was investigated by identifying the areas where gypsum was present at different amounts on the fragment surface. With this purpose, PCA was applied to the NIR data-cube in the 1300-1615 nm spectral range. Figure $5 b$ illustrates the loading plots of the first three PCs in the NIR range, whereas Figure $6 \mathrm{~b}$ shows the RGB false color maps obtained, assigning PC1 to R, PC2 to G and PC3 to B channels. Apparently, these maps fully agreed with those obtained in the Vis range. In particular, the light yellow (Red + Green) areas corresponded to the zones cleaned with two wavelengths, which resulted in complete gypsum removal. Furthermore, the corresponding spectra appeared affected mainly in the 1450-1550 nm range, which was the region where PC2 (G) and PC1 (R) had higher overlapping. Overall, the distribution maps enabled a prompt visualization of zones where removal was complete and where it was only partial. Although PCA could be used to identify directly the materials distribution, 
this method proved to be effective in mapping different spectral responses that, in turn, provided relevant information on the cleaning degree of the fragment surface.

To confirm previous results, the SAM algorithm was also applied to the spectra extracted from the SWIR cubes. The three spectra reported in Figure $4 \mathrm{~b}$ were selected as endmembers, so that areas with similar spectral features could be mapped. Thus, the yellow color was associated to spectrum P1 (areas cleaned with treatment b), the red color to spectrum P2 (areas cleaned with treatment a) and the green color to spectrum P3 (untreated areas). The map obtained (Figure 7a) was fully consistent with the false color maps obtained by PCA in reproducing the distribution of the three areas. These results confirmed that the effects of different laser cleaning treatments could be easily mapped based on HSI surface spectral features (see also Figure $7 \mathrm{~b}$ for a direct comparison of the fragment treated and untreated areas).

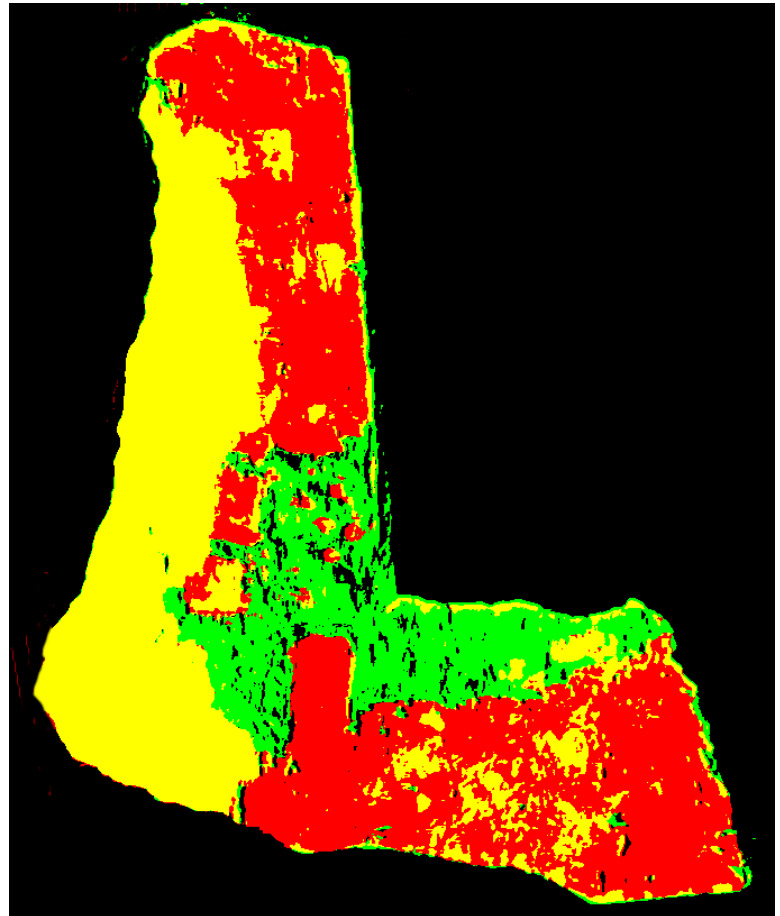

(a)

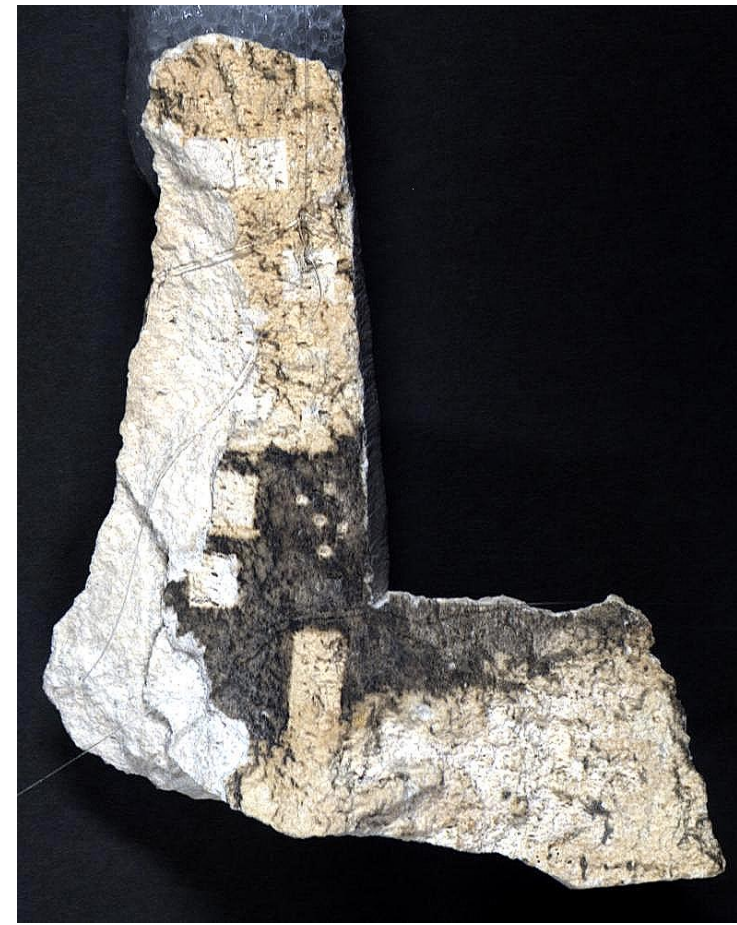

(b)

Figure 7. The spectral angle mapper (SAM) classification map applied to the 950-1650 nm range (a). Endmembers spectra are those of P1, P2 and P3 reported in Figure 4b. The RGB image reconstructed from the HSI data for a direct comparison with the map and a visual localization of the treated and untreated areas $(\mathbf{b})$.

\section{Conclusions}

The FORS-HSI approach used in this study was proven as being able to provide significant information on the outcomes of different laser cleaning treatments of an altered limestone fragment collected from a historical building. The results obtained by using two different data treatment methods, i.e., PCA and SAM, clearly demonstrated the performance of HSI to assess the effects of laser cleaning procedures by means of maps that clearly highlighted the areas where residual components of the weathered stone were distributed. This approach would offer a tool to choose the best parameters for cleaning by performing additional tests to compare the effect of different wavelengths laser pulses.

The results obtained in this work confirmed those obtained in previous studies $[34,40]$ in that the black crust deposit consisted mainly of cryptocrystalline gypsum mixed with calcite possibly combined with soot and dust deposits. The formation of gypsum on the surface of the monument stone fragment studied in this work could be attributed to the effect of rain and rain-wash. 
Finally, the fact that maps obtained in the NIR range 900-1700 nm were fully consistent with those obtained in the Vis-NIR range (400-900 nm) would encourage further studies aiming at developing protocols to evaluate cleaning operations in real time, in-field, using the last generation of compact portable HSI cameras operating in the 400-1000 nm range, which, however, feature a lower spectral quality.

Author Contributions: Conceptualization, G.S.S. and C.C.; methodology, C.C. and G.S.S.; software, C.C.; validation, C.C.; formal analysis, C.C. and G.S.S.; investigation, C.C. and G.S.S.; resources, C.C., G.S.S. and O.D.P.; data curation, C.C. and G.S.S.; writing—original draft preparation, G.S.S.; writing—review and editing, C.C., G.S.S. and O.D.P.; supervision, G.S.S. All authors have read and agreed to the published version of the manuscript.

Funding: This research received no external funding.

Acknowledgments: C.C. kindly acknowledges Andrea Casini (IFAC-CNR senior associate) for fruitful discussions and suggestions in the HSI measurements.

Conflicts of Interest: The authors declare no conflict of interest.

\section{References}

1. Dell'Anna, L.; Laviano, R. Cretaceous limestone in historic buildings and monuments of Apulia (Southern Italy): Geochemical and mineralogical characteristics and decay. Plinius 1990, 2, 51-53.

2. Smith, B.J.; Gomez-Heras, M.; Viles, H.A. Underlying issues on the selection, use and conservation of building limestone. In Limestone in the Built Environment: Present-Day Challenges for the Preservation of the Past; Smith, B.J., Gomez-Heras, M., Viles, H.A., Cassar, J., Eds.; Geological Society Special Publications: London, UK, 2010; pp. 1-11.

3. Bell, F.G. Durability of carbonate rock as building stone with comments on its preservation. Environ. Earth Sci. 1993, 21, 187-200. [CrossRef]

4. Price, C.A.; Amoroso, G.G.; Fassina, V. Stone Decay and Conservation: Atmospheric Pollution, Cleaning, Consolidation and Protection. Stud. Conserv. 1984, 29, 158. [CrossRef]

5. Sabbioni, C. Contribution of atmospheric deposition to the formation of damage layers. Sci. Total Environ. 1995, 167, 49-55. [CrossRef]

6. Belfiore, C.M.; Barca, D.; Bonazza, A.; Comite, V.; La Russa, M.F.; Pezzino, A.; Ruffolo, S.A.; Sabbioni, C.; Sabbioni, C. Application of spectrometric analysis to the identification of pollution sources causing cultural heritage damage. Environ. Sci. Pollut. Res. 2013, 20, 8848-8859. [CrossRef] [PubMed]

7. Siano, S.; Agresti, J.; Cacciari, I.; Ciofini, D.; Mascalchi, M.; Osticioli, I.; Mencaglia, A.A. Laser cleaning in conservation of stone, metal, and painted artifacts: State of the art and new insights on the use of the Nd:YAG lasers. Appl. Phys. A 2011, 106, 419-446. [CrossRef]

8. Quist, W.J.; Van Bommel, A.J. The Noble Patina of Age. In The Ageing of Materials and Structures; Van Breugel, K., Koleva, D., Van Beek, T., Eds.; Springer: Cham, Switzerland, 2018; pp. 153-165.

9. Zanini, A.; Trafeli, V.; Bartoli, L. The laser as a tool for the cleaning of Cultural Heritage. IOP Conf. Ser. Mater. Sci. Eng. 2018, 364, 012078. [CrossRef]

10. Rodrigues, J.D. Defining, mapping and assessing deterioration patterns in stone conservation projects. J. Cult. Herit. 2015, 16, 267-275. [CrossRef]

11. Sabatini, G.; Giamello, M.; Pini, R.; Siano, S.; Salimbeni, R. Laser cleaning methodologies for stone façades and monuments: Laboratory analyses on lithotypes of Siena architecture. J. Cult. Herit. 2000, 1, S9-S19. [CrossRef]

12. Brimblecombe, P.; Grossi, C.M. Aesthetic thresholds and blackening of stone buildings. Sci. Total Environ. 2005, 349, 175-189. [CrossRef]

13. Asmus, J.F.; Seracini, M.; Zetler, M.J. Surface morphology of laser-cleaned stone. Lithoclastia 1976, 1, $23-46$.

14. Cooper, M. Laser Cleaning in Conservation: An Introduction; Butterworth-Heinemann: Oxford, UK, 1998.

15. Pini, R.; Salimbeni, R. Tecniche e Sistemi Laser per il Restauro dei Beni Culturali; Cardini Editore: Firenze, Italy, 2001.

16. Fotakis, C.; Kautek, W.; Castillejo, M. Lasers in the Preservation of Cultural Heritage. Laser Chem. 2007, 2006, 1. [CrossRef] 
17. Gobernado-Mitre, I.; Prieto, A.C.; Zafiropulos, V.; Spetsidou, Y.; Fotakis, C. On-Line Monitoring of Laser Cleaning of Limestone by Laser-Induced Breakdown Spectroscopy and Laser-Induced Fluorescence. Appl. Spectrosc. 1997, 51, 1125-1129. [CrossRef]

18. Senesi, G.S.; Carrara, I.; Nicolodelli, G.; Milori, D.M.B.P.; De Pascale, O. Laser cleaning and laser-induced breakdown spectroscopy applied in removing and characterizing black crusts from limestones of Castello Svevo, Bari, Italy: A case study. Microchem. J. 2016, 124, 296-305. [CrossRef]

19. Anglos, D. Laser-induced breakdown spectroscopy in heritage science. Phys. Sci. Rev. 2019, 4, 20180005. [CrossRef]

20. Lee, J.; Watkins, K. In-process monitoring techniques for laser cleaning. Opt. Lasers Eng. 2000, 34, 429-442. [CrossRef]

21. Picollo, M.; Bacci, M.; Casini, A.; Lotti, F.; Porcinai, S.; Radicati, B.; Stefani, L. Fiber Optics Reflectance Spectroscopy: A Non-destructive Technique for the Analysis of Works of Art. In Optical Sensors and Microsystems; Martellucci, S., Chester, A.N., Mignani, A.G., Eds.; Springer: Boston, MA, USA, 2002; pp. 259-265.

22. Dupuis, G.; Elias, M.; Simonot, L. Pigment Identification by Fiber-Optics Diffuse Reflectance Spectroscopy. Appl. Spectrosc. 2002, 56, 1329-1336. [CrossRef]

23. Cheilakou, E.; Troullinos, M.; Koui, M. Identification of pigments on Byzantine wall paintings from Crete (14th century AD) using non-invasive Fiber Optics Diffuse Reflectance Spectroscopy (FORS). J. Archaeol. Sci. 2014, 41, 541-555. [CrossRef]

24. Bacci, M.; Bellucci, R.; Frosinini, C.; Picollo, M.; Porcinai, S.; Radicati, B.; Cucci, C. Fiber Optics Reflectance Spectroscopy in the Entire VIS-IR Range: A Powerful Tool for the Non-invasive Characterization of Paintings. In Materials Issues in Art and Archaeology Materials Research Society Symposium Proceedings; Vandiver, P., Mass, J., Murray, A., Eds.; Cambridge University Press: Cambridge, UK, 2005; Volume 852, pp. 297-302.

25. Fischer, C.; Kakoulli, I. Multispectral and hyperspectral imaging technologies in conservation: Current research and potential applications. Stud. Conserv. 2006, 51, 3-16. [CrossRef]

26. Cucci, C.; Delaney, J.K.; Picollo, M. Reflectance Hyperspectral Imaging for Investigation of Works of Art: Old Master Paintings and Illuminated Manuscripts. Accounts Chem. Res. 2016, 49, 2070-2079. [CrossRef]

27. Cucci, C.; Casini, A. Hyperspectral imaging for artworks investigation. Data Handl. Sci. Technol. 2020, 32, 583-604. [CrossRef]

28. Delaney, J.K.; Ricciardi, P.; Glinsman, L.D.; Facini, M.; Thoury, M.; Palmer, M.; De La Rie, E.R. Use of imaging spectroscopy, fiber optic reflectance spectroscopy, and X-ray fluorescence to map and identify pigments in illuminated manuscripts. Stud. Conserv. 2014, 59, 91-101. [CrossRef]

29. Cucci, C.; Picollo, M.; Chiarantini, L.; Uda, G.; Fiori, L.; De Nigris, B.; Osanna, M. Remote-sensing hyperspectral imaging for applications in archaeological areas: Non-invasive investigations on wall paintings and on mural inscriptions in the Pompeii site. Microchem. J. 2020, 158, 105082. [CrossRef]

30. Dooley, K.A.; Conover, D.M.; Glinsman, L.D.; Delaney, J.K. Complementary Standoff Chemical Imaging to Map and Identify Artist Materials in an Early Italian Renaissance Panel Painting. Angew. Chem. 2014, 126, 13995-13999. [CrossRef]

31. Greenberger, R.N.; Mustard, J.F.; Ehlmann, B.L.; Blaney, D.L.; Cloutis, E.A.; Wilson, J.H.; Green, R.O.; Fraeman, A.A. Imaging spectroscopy of geological samples and outcrops: Novel insights from microns to meters. GSA Today 2015, 25, 4-10. [CrossRef]

32. Pouli, P.; Zafiropulos, V.; Balas, C.; Doganis, Y.; Galanos, A. Laser cleaning of inorganic encrustation on excavated objects: Evaluation of the cleaning result by means of multi-spectral imaging. J. Cult. Herit. 2003, 4, 338-342. [CrossRef]

33. Pozo-Antonio, J.; Fiorucci, M.; Ramil, A.; López, A.J.; Rivas, T. Evaluation of the effectiveness of laser crust removal on granites by means of hyperspectral imaging techniques. Appl. Surf. Sci. 2015, 347, 832-838. [CrossRef]

34. Senesi, G.S.; Nicolodelli, G.; Milori, D.M.B.P.; De Pascale, O. Depth profile investigations of surface modifications of limestone artifacts by laser-induced breakdown spectroscopy. Environ. Earth Sci. 2017, 76, 565. [CrossRef] 
35. Cucci, C.; Casini, A.; Picollo, M.; Stefani, L. Extending hyperspectral imaging from Vis to NIR spectral regions: A novel scanner for the in-depth analysis of polychrome surfaces. In Proceedings of the Optics for Arts, Architecture, and Archaeology IV, Munich, Germany, 15-16 May 2013; The International Society for Optical Engineering SPIE: Washington, DC, USA, 2013; Volume 8790, p. 879009. [CrossRef]

36. Rodarmel, C.; Shan, J. Principal component analysis for hyperspectral image classification. Surv. Land Inf. Sci. 2002, 62, 115-122.

37. Kruse, F.; Lefkoff, A.; Boardman, J.; Heidebrecht, K.; Shapiro, A.; Barloon, P.; Goetz, A. The spectral image processing system (SIPS)-Interactive visualization and analysis of imaging spectrometer data. Remote Sens. Environ. 1993, 44, 145-163. [CrossRef]

38. Harris Geospatial Solutions, Spectral Angle Mapper. Available online: https://www.harrisgeospatial.com/ docs/SpectralAngleMapper.html (accessed on 20 November 2020).

39. Clark, R.N.; King, T.V.V.; Klejwa, M.; Swayze, G.A.; Vergo, N. High spectral resolution reflectance spectroscopy of minerals. J. Geophys. Res. Space Phys. 1990, 95, 12653-12680. [CrossRef]

40. Senesi, G.S.; Campanella, B.; Grifoni, E.; Legnaioli, S.; Lorenzetti, G.; Pagnotta, S.; Poggialini, F.; Palleschi, V.; De Pascale, O. Elemental and mineralogical imaging of a weathered limestone rock by double-pulse micro-Laser-Induced Breakdown Spectroscopy. Spectrochim. Acta Part B At. Spectrosc. 2018, 143, 91-97. [CrossRef]

Publisher's Note: MDPI stays neutral with regard to jurisdictional claims in published maps and institutional affiliations.

(C) 2020 by the authors. Licensee MDPI, Basel, Switzerland. This article is an open access article distributed under the terms and conditions of the Creative Commons Attribution (CC BY) license (http://creativecommons.org/licenses/by/4.0/). 